Article

\title{
National-Scale Estimates of Ground-Level PM2.5 \\ Concentration in China Using Geographically Weighted Regression Based on 3 km Resolution MODIS AOD
}

\author{
Wei You, Zengliang Zang *, Lifeng Zhang, Yi Li, Xiaobin Pan and Weiqi Wang \\ Institute of Meteorology and Oceanography, PLA University of Science and Technology, Nanjing 211101, China; \\ youweilx@gmail.com (W.Y.); lifzhangqxxy@163.com (L.Z.); yiliqxxy@163.com (Y.L.); xbpqxxy@163.com (X.P.); \\ haozl07@lzu.edu.cn (W.W.) \\ * Correspondence: zzlqxxy@163.com; Tel./Fax: +86-025-8083-0400
}

Academic Editors: Alexander A. Kokhanovsky and Prasad S. Thenkabail

Received: 20 October 2015; Accepted: 5 February 2016; Published: 26 February 2016

\begin{abstract}
High spatial resolution estimating of exposure to particulate matter 2.5 (PM2.5) is currently very limited in China. This study uses the newly released nationwide, hourly PM2.5 concentrations to create a nationwide, geographically weighted regression (GWR) model to estimate ground-level PM2.5 concentrations in China. A3 km resolution aerosol optical depth (AOD) product from MODIS is used as the primary predictor. Fire emissions detected by MODIS fire count were considered in the model development process. Additionally, meteorological features were used as covariates in the model to improve the estimation of ground-level PM2.5 concentrations. The model performed well and explained $81 \%$ of the daily PM2.5 concentration variations in model predictions, and the cross validations $\mathrm{R}^{2}$ is 0.79 . The cross-validated root mean squared error (RMSE) of the model was $18.6 \mu \mathrm{g} / \mathrm{m}^{3}$. Annual PM2.5 concentrations retrieved by the MODIS $3 \mathrm{~km}$ AOD product indicated that most of the residential community areas exceeded the new annual Chinese PM2.5 National Standard level 2. Estimated high-resolution national-scale daily PM2.5 maps are useful to identify severe air pollution episodes and determine health risk assessments. These results suggest that this approach is useful for estimating large-scale ground-level PM2.5 distributions, especially for regions without PM monitoring sites.
\end{abstract}

Keywords: aerosol optical depth; PM2.5; MODIS; air pollution; geographically weighted regression

\section{Introduction}

Aerosols or airborne particulate matters (PMs), which originate from both natural and anthropogenic emission sources, substantially influence the climate, environment and human health [1]. Numerous epidemiological studies have demonstrated that exposure to ambient PMs is associated with various adverse health outcomes [2-4]. With intensive economic development and industrial reconstruction, China has endured extremely high PM2.5 concentrations in recent years. Consequently, the accurate assessment of air quality, particularly in terms of PM2.5 (particulate matter with an aerodynamic diameter less than $2.5 \mu \mathrm{m}$ ) and its spatiotemporal variability, is currently a pressing issue.

Ground-based monitoring networks canprovide important information on atmospheric PM2.5 concentration and composition. However, the spatial coverage of routine measurements is still limited and thus often insufficient to obtain the spatial variability of PM2.5 concentration. Furthermore, the Ministry of Environmental Protection (MEP) of China only began carrying out routine monitoring of PM2.5 in major cities (e.g., Beijing and Guangzhou City) since the beginning of 2013. Inadequacy 
of spatially and temporally continuous ground-based PM2.5 monitoring networks contributes to the difficulty in estimating the historical spatial and temporal variation of PM2.5 concentrations, especially on a regional scale, and hinges on restrained epidemiological studies of PM2.5 in China [5].

Satellite-derived aerosol optical depths (AODs) have been widely used to monitor surface PM2.5 concentrations [6-8]. Satellite remote sensed AOD represents columnar aerosol loading of the atmosphere and can be empirically converted into PM mass. To date, a number of empirical models have been developed to estimate ground-level PM concentration from satellite-derived AOD products for different parts of the world [7,9-11]. To improve the accuracy of PM2.5 estimation, more advanced models have been set-up over the past few years, such as hybrid models and mixed effective models [12-17]. Nevertheless, the strength of the AOD-PM2.5 relationship varies widely by region, and the relationships in certain regions may not be applicable to other regions [18,19].

Although a variety of advanced models of PM2.5 estimation have been made in China [5,20-24], most of these studies were limited to specific cities or regions. In addition, most of these studies have used lower resolution $(\sim 10 \mathrm{~km})$ AOD products in estimating PM2.5 concentration. This commonly used resolution of AOD products is often too coarse and thus insufficient to determine exposure estimates in urban areas. Until recently, the widely anticipated $3 \mathrm{~km}$ MODIS AOD product (Collection 6) has been released [25]. Furthermore, the major cities in all provinces have released hourly PM2.5 concentrations to the public since 2013 through a nationwide air quality monitoring network, which provides data for higher resolution AOD and hourly PM2.5 modeling.

By taking advantage of the newly established national PM2.5 monitoring network and utilizing the newly released $3 \mathrm{~km}$ resolution AOD products, in this paper, we established a national-scale satellite based geographically weighted regression (GWR) model to estimate ground-level PM2.5. To improve accuracy, we considered fire emissions in the GWR model development process as previous studies have reported that biomass burning can affect AOD-PM2.5 relations [23,26].

This paper is organized as follows. Section 2 describes the methods of processing the data from different sources and the methodology that we used to establish the relationship between AOD and hourly PM2.5 concentration. Section 3 shows the results of the performance of model. Several potential sources of prediction error of the GWR model is discussed in Section 4. The summary and conclusion are given in Section 5 .

\section{Materials and Methods}

\subsection{Data Collection and Reprocessing}

\subsubsection{Ground-Based Hourly PM2.5 Concentration Data}

More than 900 ambient air-quality monitoring sites were set up in China by the Ministry Environmental Protection (MEP) and local environmental protection agencies (Figure 1) for the purpose of protecting ambient air quality. These sites monitor the mass concentration of particulate air pollutants on the ground. The PM2.5 data from these sites include hourly mass concentrations and $24 \mathrm{~h}$ average concentrations (daily-mean). Hourly PM2.5 measurements from 1 January 2014 to 31 December 2014 were collected primarily from the official Web site of the China Environmental Monitoring Center (CEMC) [27]. A total of 943 monitoring sites are included in the present study (Figure 1). 

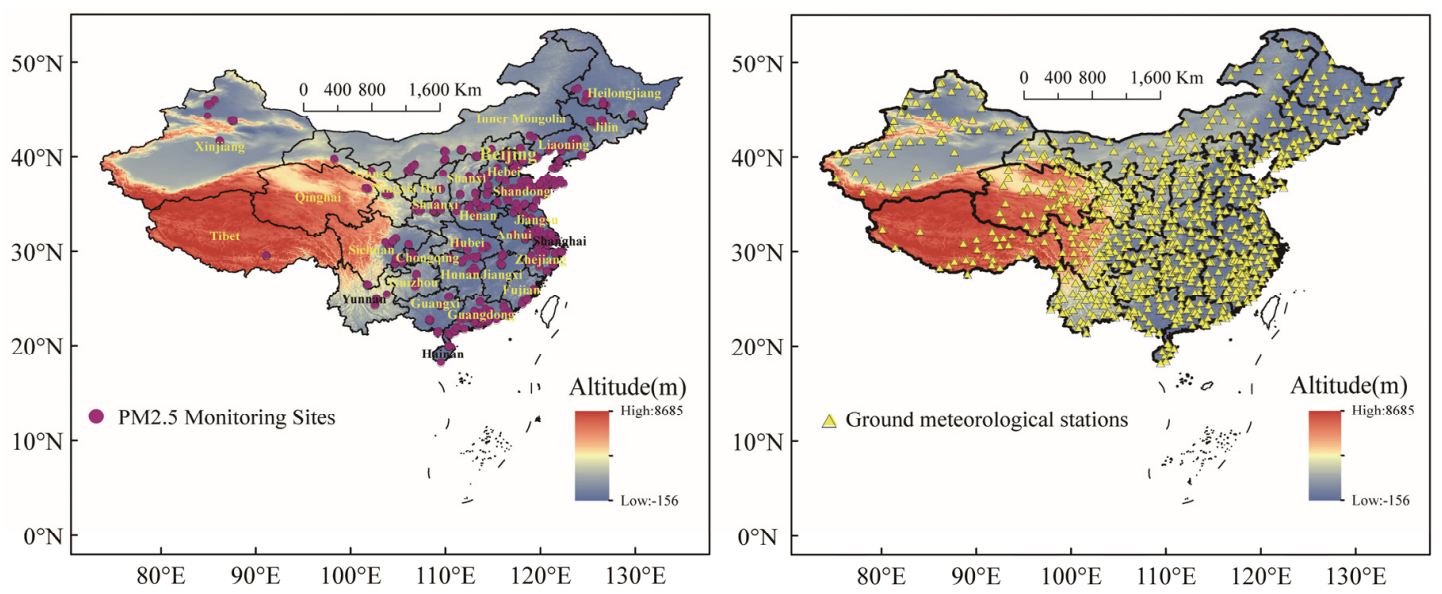

Figure 1. Spatial distribution of the air-quality monitoring stations (violet dots) and meteorological stations (yellow triangles) used in this study. There are 943 particulate matter 2.5 (PM2.5) monitoring sites and 926 ground meteorological stations. It should be noted that the monitoring sites are clustered in the urban areas of major cities, whereas rural areas have little coverage. Many monitoring sites are overlaid in this map.

\subsubsection{Satellite AOD Datasets}

Two MODIS instruments were put onboard the Terra satellite in December 1999 and the Aqua satellite in May 2002. Both instruments collect AOD data. Recently, more accurate MODIS collection 6 (C6) AOD products were released at a spatial resolution of $3 \mathrm{~km}$ at nadir. In addition, these newly released AOD products have been validated by AOD observations from 33 Aerosol Robotic Network (AERONET) sites in China and the results were satisfactory [28]. Detailed information on the Collection 6 (C6) retrieve algorithm can be found elsewhere [29,30].

The Terra and Aqua satellites cross the equator at approximately 10:30 a.m. and 1:30 p.m. local solar time (LST), respectively. The data acquired during the daytime passes of both MODIS instruments are used here. The global MODIS Level 2 Aerosol Products for 2014 (Collection 6) can be downloaded from the website [31]. In this study, we used the values of both MODIS Terra (MOD04) and MODIS Aqua (MYD04) AOD, which were extracted at $550 \mathrm{~nm}$.

The MODIS Active Fire product provided by Information for Resource Management System (FIRMS) was used to detect the fire emission in China. The original data are processed by MODIS Adaptive Processing System (MODAPS) using the enhanced contextual fire detection algorithm into the Collection 5 Active fire product [32]. The fire data are at a spatial resolution of $1 \mathrm{~km}$. For this study, we have considered both the total fire number and high-confidence fire counts spanning from 1 January 2014 to 31 December 2014.

\subsubsection{Ground-Based Meteorological Measurements}

Ground-based meteorological parameters, including surface wind speed (SPD), surface air temperature (ST), horizontal visibility (Vis), and surface relative humidity (SRH), were collected from 926 meteorological stations (Figure 1). Corresponding to ground-based PM2.5 measurements, the meteorological data used were from 1 January 2014 through 31 December 2014 and was provided by the China Meteorological Center. The measurements at these stations were made every three hours.

\subsubsection{Data Preprocessing and Integration}

Because the data from the three sources have different temporal and spatial resolutions, all datasets were re-processed to be consistent in space and time to form a complete dataset that can be used as the basis of the following analyses. For the retrieved AOD data from both Terra and Aqua satellites, we used the nearest of AOD pixel over a window size of $3 \times 3$ pixels centered at a given PM2.5 station 
for our analysis. For example, we applied a $9 \mathrm{~km}$ search radius around each PM2.5 monitoring site and the MODIS AOD pixels with shortest distance to the PM2.5 station were used. Furthermore, to avoid possible cloud contamination, we eliminated all of the AOD-PM2.5 pairs where the number of pixels is less than two. In addition, to reduce the possibility of including spurious AOD pixels, we removed AOD pixels with a standard deviation of greater than 0.5. As the AOD data from Terra and Aqua were collected two different times each day, we used its average as the mean AOD value.

Corresponding to the period of the AOD data, 3-h surface meteorological data were re-processed by averaging values at 11:00 a.m. and 2:00 p.m. and hourly PM2.5 observations were sampled from 10:00 a.m. to 2:00 p.m. LST (corresponding to the satellite overpass times). The surface meteorological data from the closest meteorological station were used to represent the meteorological conditions for each PM2.5 monitoring station. To select the meteorological station, we applied a $150 \mathrm{~km}$ search radius around each PM2.5 monitoring station and the meteorological station in closest proximity to the PM2.5 station was used. The final paired dataset contains 30,130 samples, which was used for the following analysis.

\subsection{Methodology}

\subsubsection{Detection of Fire Emissions}

Crop residues burning in the field is a common approach used to eliminate agricultural waste for next crop in line and to enrich soil nutrients, and this practice is more prevalent during the harvest season in China. In addition, crop residue burning as fuel and in the field is the major source of biomass burning in China [33].

Figure 2 displays the annual distribution of fire counts collected from both Terra and Aqua satellites. There were a total of 287,332 fire spots detected by satellite in our study area during 2014. Fire occurrence was highest in the summer and lowest in the winter. A previous study reported that biomass burning can produce aerosols above the boundary layer, which could eliminate AOD-PM relationships [23]. Thus, we chose to exclude all of the AOD-PM2.5 pairs where one or more high confidence fires was detected within a window size of $3 \times 3$ AOD pixels centered at a given PM2.5 site.

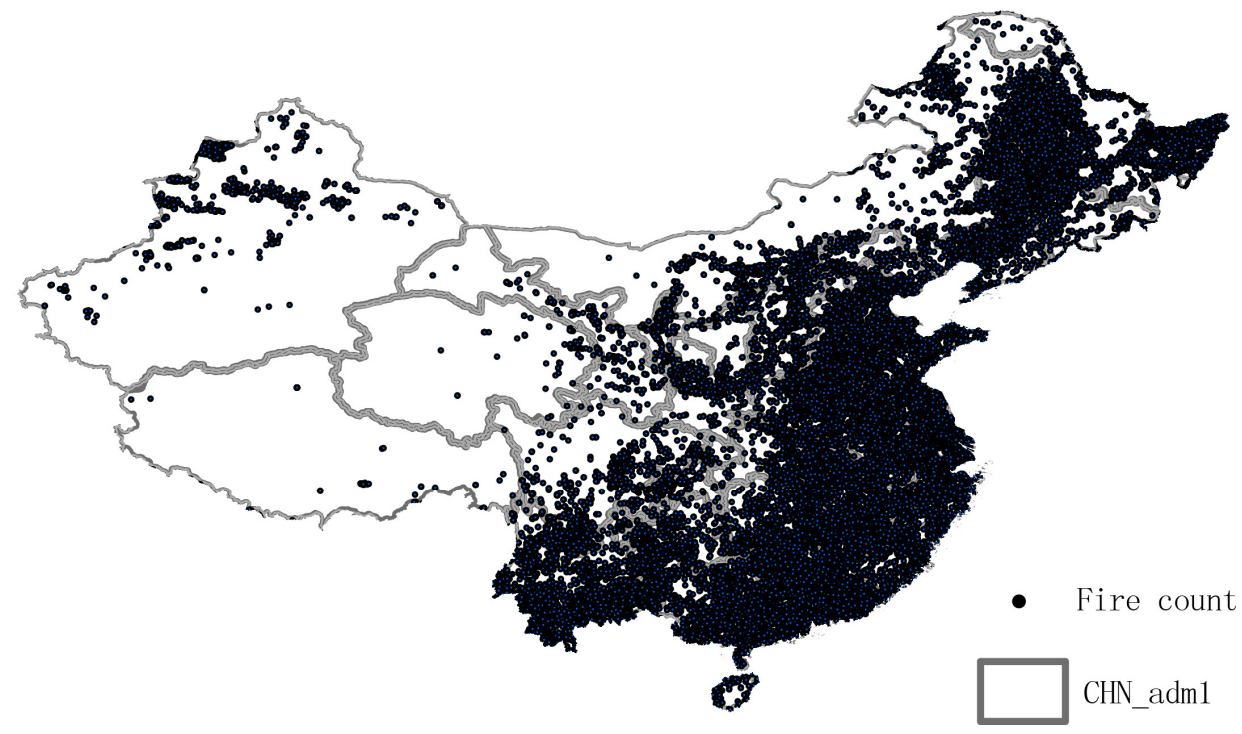

Figure 2. The annual distribution of fire counts in China in 2014.

\subsubsection{Model Development and Validation}

Our previous study developed a GWR model to estimate ground-level particulate matter 10 (PM10) in a specific city in northwest China and the model performed well in Xi'an [23]. We extend 
our previous satellite methodology to the national-scale. Using a novel $3 \mathrm{~km}$ resolution MODIS AOD product, we estimated national-scale daily PM2.5 concentration in China. We calibrated the AOD-PM2.5 relation using newly released national-wide hourly PM2.5 ground monitors and meteorological parameters.

It has been established that the association of AOD and ground-level PM2.5 varies spatially and temporally, and changes with spatial context (Figure 3). Such spatial variability of the relationship may be attributed to several differences, including meteorological patterns and seasonality. A GWR model can be used to explore geographically varying relationships between dependent variables and independent variables. GWR model has been successfully adopted in modeling the PM2.5-AOD association in China [5,21]. GWR model can generate a continuous surface of parameter values by taking measurements of the parameters at each local observation to denote the spatial variations of the surface [5,34]. To account for these temporal variations in the PM2.5-AOD relationship, a GWR model was established to obtain a local $\mathrm{R}^{2}$ for each PM2.5 monitoring site on a daily basis. The adaptive bandwidths were chosen as the uneven distribution of the monitoring sites. The detail of GWR model structure is expressed in the following equation:

$$
\mathrm{PM} 2.5_{\mathrm{ij}}=\beta_{0, \mathrm{ij}}+\beta_{1, \mathrm{ij}} \mathrm{AOD}_{\mathrm{ij}}+\beta_{2, \mathrm{ij}} \mathrm{SRH}_{\mathrm{ij}}+\beta_{3, \mathrm{ij}} \mathrm{Vis}_{\mathrm{ij}}+\beta_{4, \mathrm{ij}} \mathrm{ST}_{\mathrm{ij}}+\beta_{5, \mathrm{ij}} \mathrm{SPD}_{\mathrm{ij}}
$$

where PM2.5 $5_{i j}\left(\mu \mathrm{g} / \mathrm{m}^{3}\right)$ is the averaged hourly ground-level PM2.5 concentration at a location $i$ on day $j ; \beta_{0, i j}$ denotes the location-specific intercept on day $j ; \beta_{1, i j}-\beta_{6, i j}$ is the location specific slopes on day $j$; $A O D_{i j}$ (unitless) is the MODIS-derived AOD (unitless) products at a location $i$ on day $j$; and $S R H_{i j}$ (unit: \%), Vis $s_{i j}$ (unit: $\mathrm{Km}$ ), $S T_{i j}$ (unit: ${ }^{\circ} \mathrm{C}$ ), and $S P D_{i j}$ (unit: $\mathrm{m} / \mathrm{s}$ ) are meteorological parameters at location $i$ on day $j$ (definitions in Section 2.1). The selection of the meteorological variables in the model is based on findings of previous study [5,23].

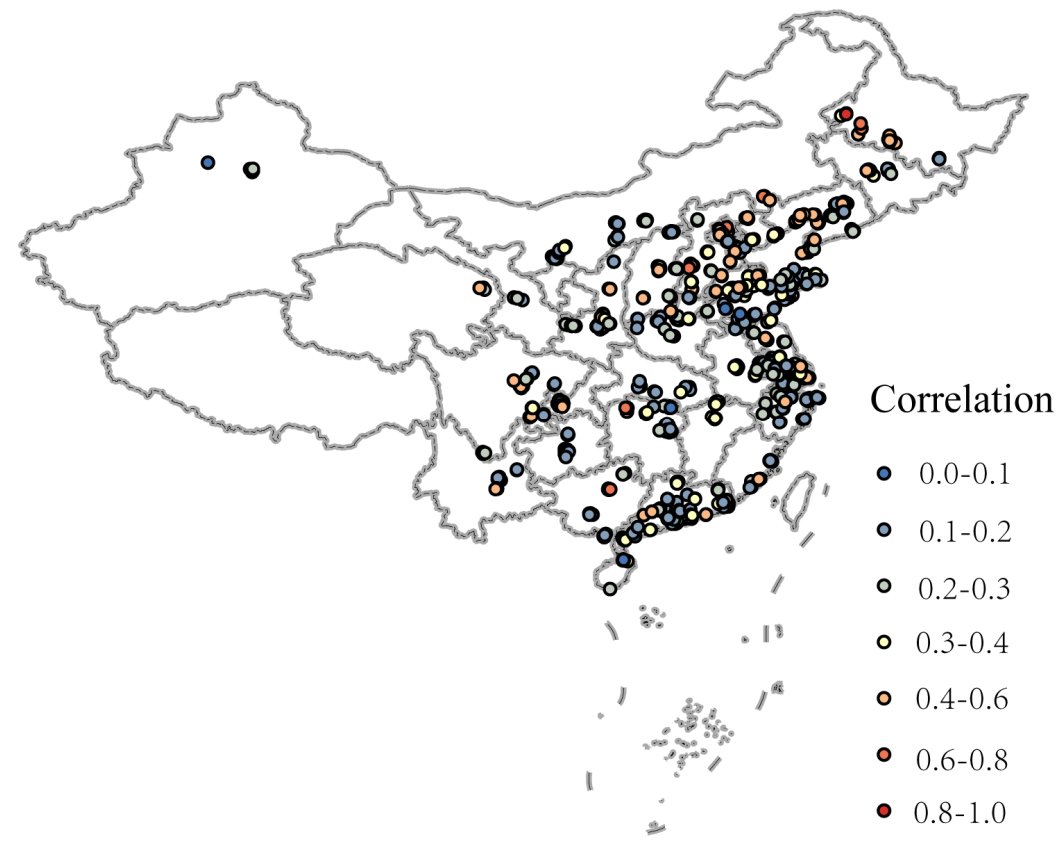

Figure 3. The distribution of Pearson correlations between AOD and PM2.5 in China.

To validate the performance of the model, the estimated PM2.5 concentrations are fitted against the observed values. In addition, commonly used factors including the correlation coefficients, mean absolute percentage prediction error (APE), and root-mean-square error (RMSE) are calculated to evaluate the degree of goodness of fit between estimated and observed PM2.5 concentrations. 
We applied a 10-fold cross validation method [35] to test for potential model over-fitting in the present study. The dataset was first broken into 10 folds with approximately $10 \%$ of the total data points in each fold. In each round of the cross validation, the model was fitted with nine folds $(90 \%$ of the total dataset) and one fold was predicted using the fitted model. This step can be repeated 10 times until every fold is tested. Furthermore, APE and RMSE are adopted to evaluate the model prediction accuracy for model fitting and cross validation results.

\section{Results}

\subsection{Descriptive Statistics}

Table 1 summarizes the descriptive statistics of dependent variables as well as PM2.5 measurements used in model fitting. The MODIS AOD has an annual mean value of 0.69 and a standard deviation (SD) of 0.45. Theannual mean ground-level PM2.5 concentrations in 2014 ranged from 2 to $494 \mu \mathrm{g} / \mathrm{m}^{3}$, with a mean value of $61 \mu \mathrm{g} / \mathrm{m}^{3}$ and SD of $41 \mu \mathrm{g} / \mathrm{m}^{3}$. The annual mean visibility values extended from 0.05 to $30 \mathrm{~km}$, and surface air temperature ranged from -9.1 to $38.1^{\circ} \mathrm{C}$. The relatively small mean value of SRH ( $40 \%)$ implies a relatively dry atmospheric environment. Surface wind speed $(3.3 \pm 1.8 \mathrm{~m} / \mathrm{s})$ is less variable when compared with other meteorological variables.

Table 1. Descriptive statistics summarizing observations for PM2.5 monitoring sites for Year 2014.

\begin{tabular}{ccccc}
\hline Parameters & Mean & SD & Min & Max \\
\hline PM2.5 $\left(\mu \mathrm{g} / \mathrm{m}^{3}\right)$ & 61.14 & 41.21 & 2.2 & 494.20 \\
MODIS AOD & 0.69 & 0.45 & 0.01 & 4.51 \\
Relative humidity $(\%)$ & 40.10 & 14.85 & 6.50 & 100.00 \\
Visibility $(\mathrm{km})$ & 16.33 & 8.83 & 0.05 & 30.00 \\
Surface air temperature $\left({ }^{\circ} \mathrm{C}\right)$ & 23.01 & 7.42 & -9.12 & 38.05 \\
Wind speed $(\mathrm{m} / \mathrm{s})$ & 3.27 & 1.78 & 0.50 & 15.00 \\
\hline
\end{tabular}

\subsection{Model Fitting and Validation}

After excluding fire emission points, there are a total of 27,813 matched predictors available for model fitting. Figure 4 shows the scatterplots for the model fitting and cross validation for the GWR model. For the model fittings, the overall $\mathrm{R}^{2}$ between the predicted and observed PM2.5 concentration is 0.81 , with a RMSE value of $17.2 \mu \mathrm{g} / \mathrm{m}^{3}$ and APE of $18.5 \%$. The model performed very well with a cross validated $\mathrm{R}^{2}$ of 0.79 , which indicated that this model can generate an accurate prediction. In comparison to the model fitting, the cross validation $\mathrm{R}^{2}$ only decreases by 0.02 , and cross validation RMSE only increases by $1.4 \mu \mathrm{g} / \mathrm{m}^{3}$ for the model, which are both greater than the model fitting and suggests that the model is not substantially over-fitted.
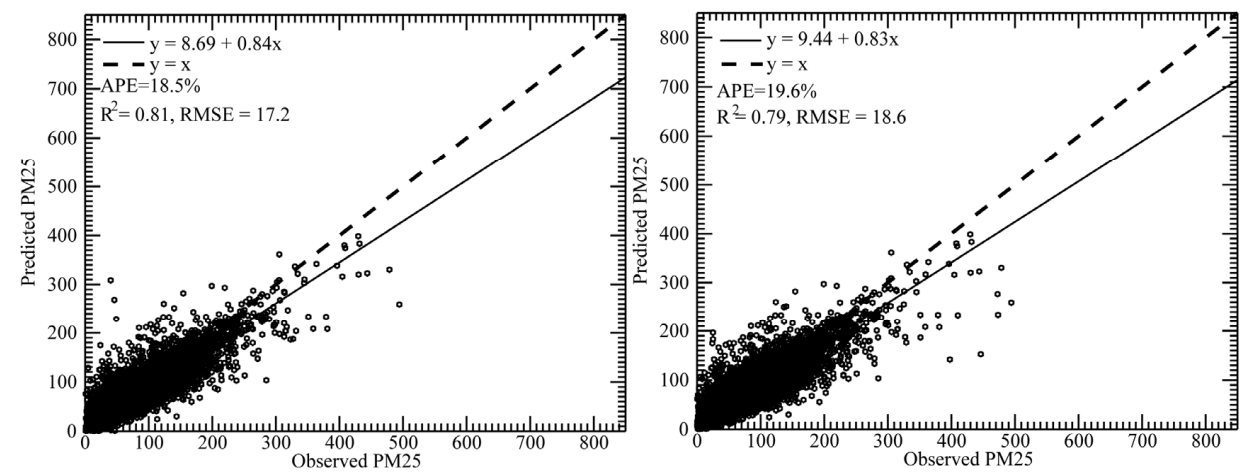

Figure 4. Results of model fitting (left) and cross validation (right). The dash line is the 1:1 line as a reference. 
Our results show that the cross validation RMSE of the model is $18.6 \mu \mathrm{g} / \mathrm{m}^{3}$, which is much lower than the results of a previous study in China [5]. The cross validation relative prediction error (RPE, defined as RMSE divided by the mean ground-level PM2.5 concentration) of the model is $31.6 \%$, which is $19.7 \%$ lower than the previous study in the China. There are several possible reasons that may contribute to the more accurate estimation generated by our model compared with the previous study. First, the PM2.5 concentrations in the previous study are daily-mean concentrations, which are averaged hourly observations. However, satellite AOD data cannot capture the diurnal variation of daily PM2.5 concentration and therefore that data cannot be well represented. In this study, the ground-based PM2.5 measurements closest to the overpass time of the satellite were selected. Hourly PM2.5 concentrations sampled from 10:00 a.m. to 2:00 p.m. LST were used to correspond to the satellite overpass times. Second, we excluded the AOD data that detected fire emissions at a given PM2.5 site in the model development process. From our previous study, we reported that crop residue burning is an important factor that leads to airborne aerosols, which can eliminate the AOD-PM relationship [23]. Third, we used a fine-resolution $3 \mathrm{~km}$ AOD product as predictors of surface PM2.5 concentrations while the previous study used $10 \mathrm{~km}$ AOD products. Another previous study reported that the model performance was more accurate using the $3 \mathrm{~km}$ AOD product than the performance based on the $10 \mathrm{~km}$ product [16]. Finally, the ground meteorological parameters used in our model obtained from ground-based observations more accurately represented surface air conditions when compared to the parameters obtained via model output in previous studies.

\subsection{Estimation of Spatial Distributions of PM2.5 Concentrations.}

Daily MODIS $3 \mathrm{~km}$ AOD and meteorological data were gridded to 0.1 degree $(\sim 10 \mathrm{~km})$ spatial resolution using the Kriging method. Subsequently, spatial distributions of PM2.5 concentration were predicted using the validated GWR model. Figure 5 shows the ground-level observed annual mean PM2.5 concentrations in China, and AOD-derived PM2.5 are shown in Figure 5.

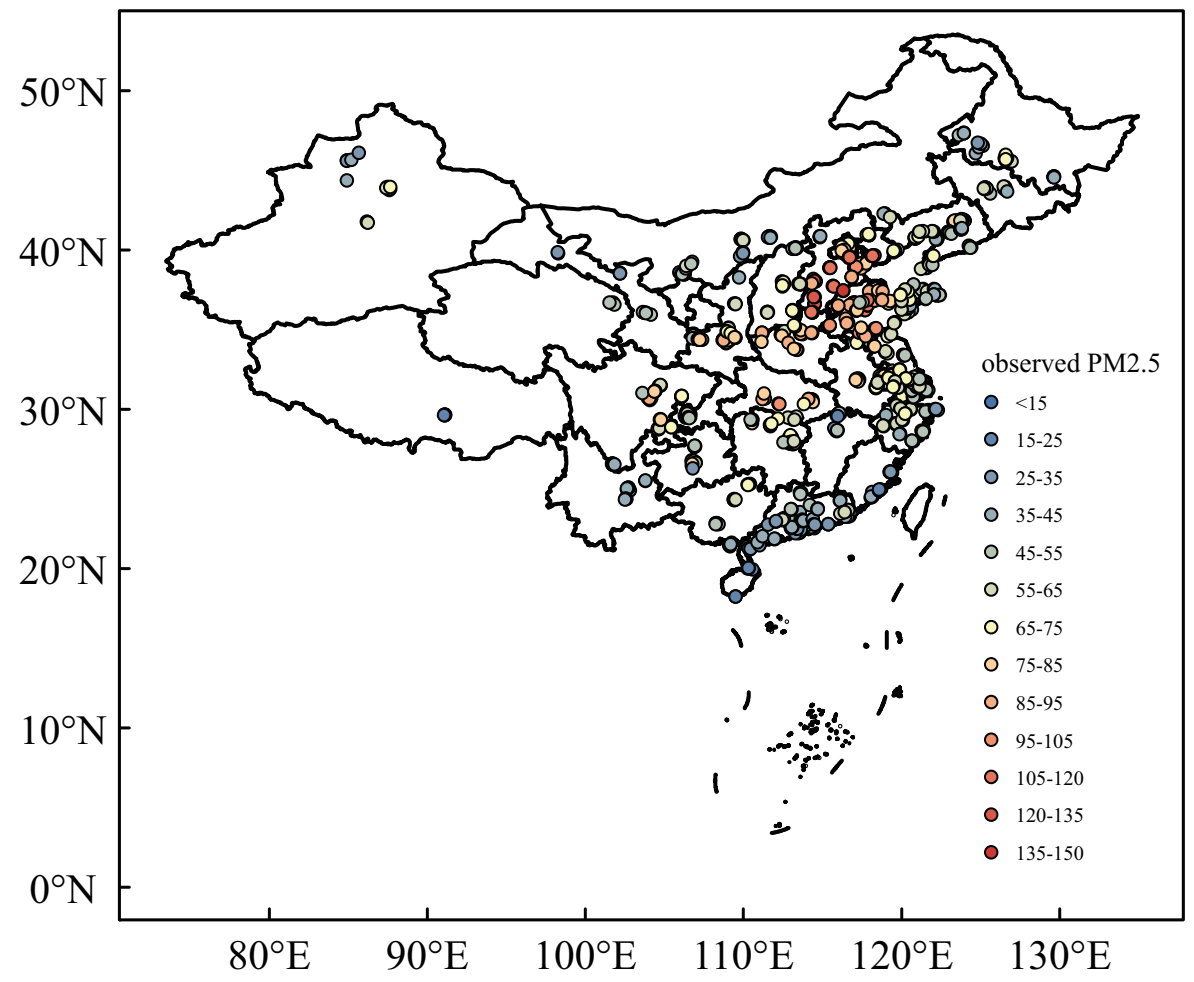

Figure 5. Annual mean ground observed PM2.5 concentrations. 
The observations from ground monitoring sites exhibited a strong heterogeneity of PM2.5 concentrations among discrete sites, while the MODIS AOD-derived PM2.5 concentrations provided a more comprehensive map of the spatial distributions of PM2.5 concentrations across China. Figures 5 and 6 show the annual averaged ground-observed PM2.5 concentrations and AOD retrieved PM2.5 concentrations from 1 January to 31 December 2014, respectively. The spatial distributions among figures are in accordance. Spatially, the highest PM2.5 loadings appear in the Beijing-Tianjin Metropolitan Region (including Beijing, Tianjin, and Hebei), followed by Central China (including Hunan, Hubei, and Henan).

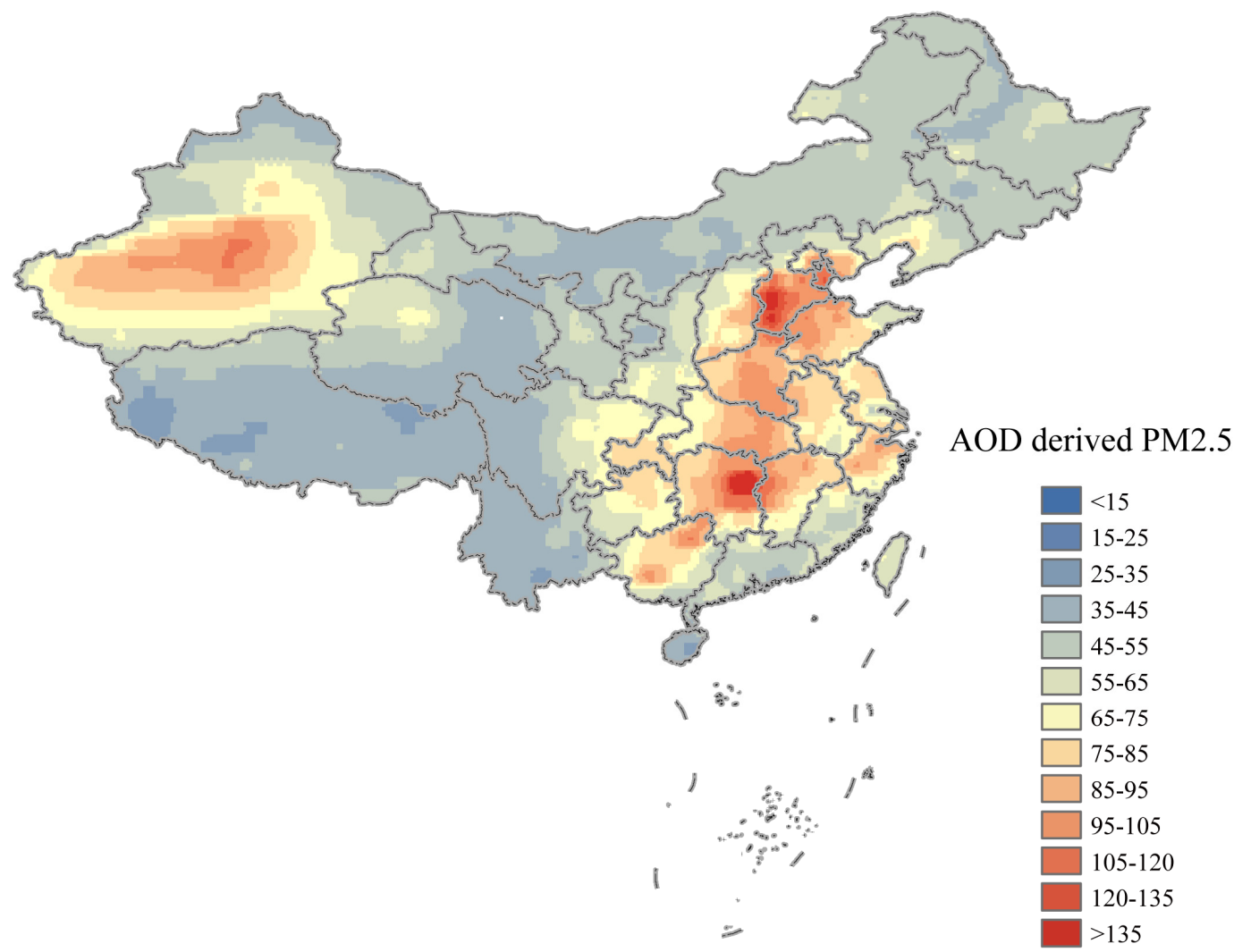

Figure 6. Annual mean MODIS AOD-derived PM2.5 concentrations.

The annual mean PM2.5 concentrations in the Beijing-Tianjin Metropolitan Region are generally higher than $85 \mu \mathrm{g} / \mathrm{m}^{3}$, with the highest concentrations greater than $135 \mu \mathrm{g} / \mathrm{m}^{3}$. The annual mean PM2.5 concentrations are generally greater than $75 \mu \mathrm{g} / \mathrm{m}^{3}$ in Central China. These regions in China have the greatest amount of industrial structures and are densely populated. Intense human activity and rapid urbanization have led to a high production of PM2.5 concentration in these regions. The Tarim Basin located in the southern part of Xinjiang Autonomous Region is another area of heavily polluted area with high PM2.5 levels. The Taklamakan Desert covers over $60 \%$ of the Tarim Basin. Dust generated in the Taklamakan Desert and Asian pollution can become entrained and transported across eastern Asia [36], and thus high level PM2.5 derived by AOD in desert regions contribute significantly to regional PM2.5 pollution in the Tarim Basin. The Chongqing Metropolitan is another area of high pollution with the annual PM2.5 concentrations of $75-85 \mu \mathrm{g} / \mathrm{m}^{3}$. Persistent temperature inversion and stagnant air circulation usually occur in this region owing to its unique topography, and thus often lead to severe air pollution. High PM2.5 concentrations also occur in the Yangtze River Delta, an area that is one of the most developed regions in China. The cleanest areas are in North Inner Mongolia, Hainan, and Tibet, where the annual mean values from both MODIS AOD are generally lower than $35 \mu \mathrm{g} / \mathrm{m}^{3}$. Heilongjiang and Yunnan Province have annual mean values of 
$25-55 \mu \mathrm{g} / \mathrm{m}^{3}$. Figure 7 shows spatial distributions of standard deviation of predicted residuals across China. Overall, the highest prediction errors appear in Northern China, Yangtze River Delta, and Hunan province, followed by eastern Heilongjiang, northern Xinjiang Province and the junction of Guangdong and Hainan Provinces.

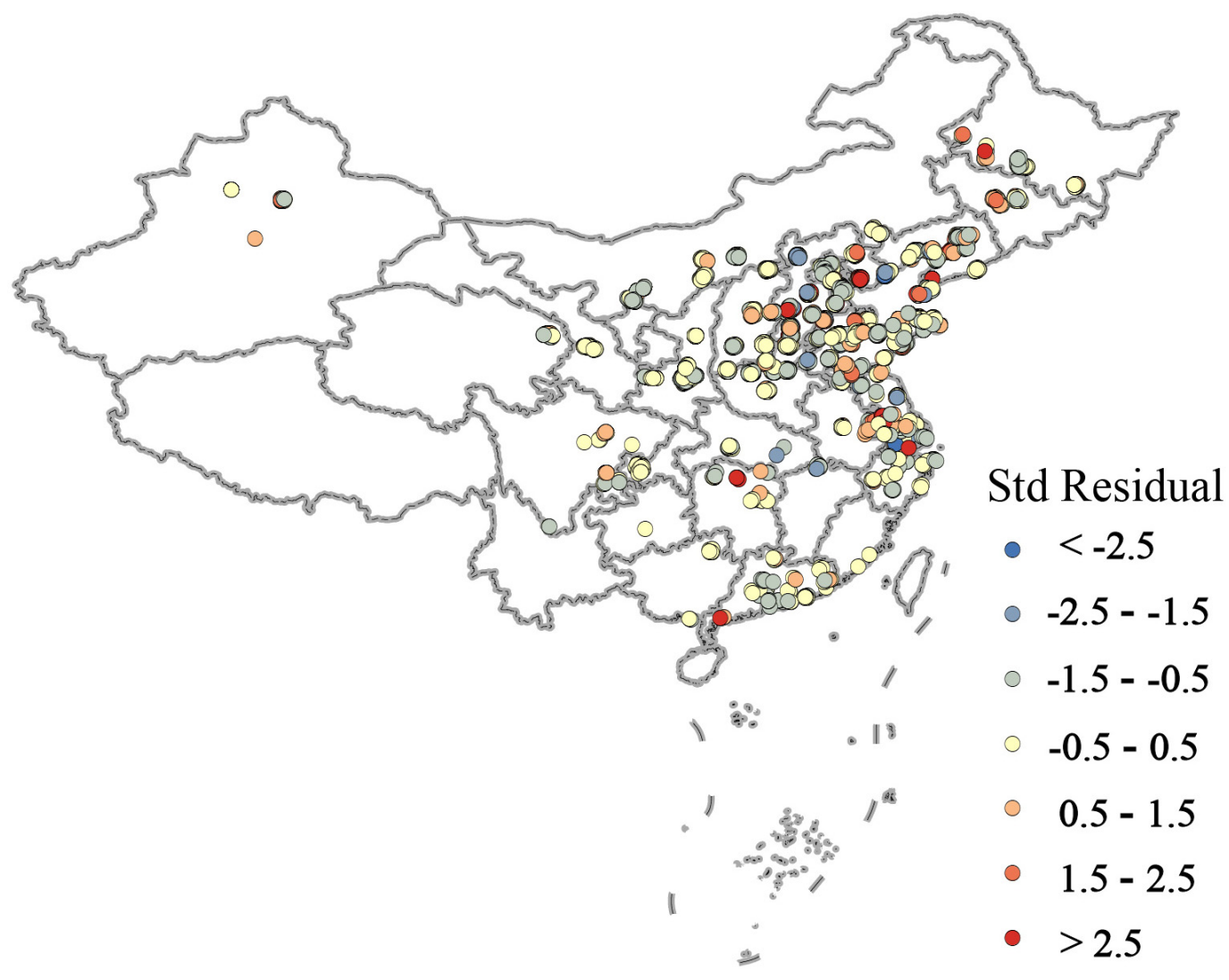

Figure 7. Annual mean standard deviation of predicted residual of the GWR model.

\section{Discussion}

In summary, the GWR model proved to have strong potential to estimate PM2.5 concentrations in China. However, it should be noted that the AOD-derived PM2.5 concentrations in several regions are substantially over-predicted. For example, the AOD-derived PM2.5 was overestimated in Hunan and Hubei Provinces, especially in eastern Hunan (Figure 8). The eastern part of Hunan Province was very over-predicted, with estimated concentrations going up to $135 \mathrm{\mu g} / \mathrm{m}^{3}$. However, the observed PM2.5 in this region is about $85 \mu \mathrm{g} / \mathrm{m}^{3}$. Similar overestimation was also found at the junction of Hunan and Hubei Provinces. There are several factors that may contribute to possible estimation errors. First, the uneven spatial distribution of ground-based PM2.5 monitors may lead to potential estimation error of the GWR model. Most of the PM2.5 monitors are located in large urban centers. Rural areas still have very limited PM2.5 monitoring site coverage, especially in the western part of the country such as Xinjiang, Tibet, Qinghai and Inner Mongolia. Therefore, the estimated PM2.5 levels in the cleaner areas of China may contain substantial errors. Nevertheless, this problem is expected to be alleviated in the near future because the national PM2.5 monitoring network will cover all county-level cities by 2015 [37]. Second, the satellite has less temporal coverage due to its sampling limitation according to retrieval algorithm (surface conditions, clouds, and other factors), especially in winter. As a previous study reported, the sampling bias by the satellite may affect the long-term mean PM2.5 derived from the AOD-based calibration model [16]. Third, although the $3 \mathrm{~km}$ MODIS AOD products have been demonstrated with satisfactory quality over China [30], improper characterization of surface reflectance 
adversely impact retrieval accuracy of the higher-resolution products [38]. Fourth, the spatial and temporal mismatch among meteorological, AOD, and pollutant data may also bring uncertainties in the PM2.5 estimating. For example, the MODIS AODs represent average value of a $3 \mathrm{~km}$ resolution at nadir. However, observed PM2.5 is a point value obtained form a given monitor site. Furthermore, we used Kriging interpolate method to grid the AOD and methodological variables. The uneven spatial distribution of these parameters may also lead to estimation errors in the interpolation process. Finally, MODIS AOD retrieval algorithm may also lead to PM2.5 estimation error in some regions such as Taklamakan and Gobi Deserts. Ideally, the MODIS operational AOD retrieval algorithm over dark surface uses the near-infrared at $2.1 \mu \mathrm{m}$, but the variance in surface reflectance in different regions can cause differences in the accuracy of AOD retrievals [19].
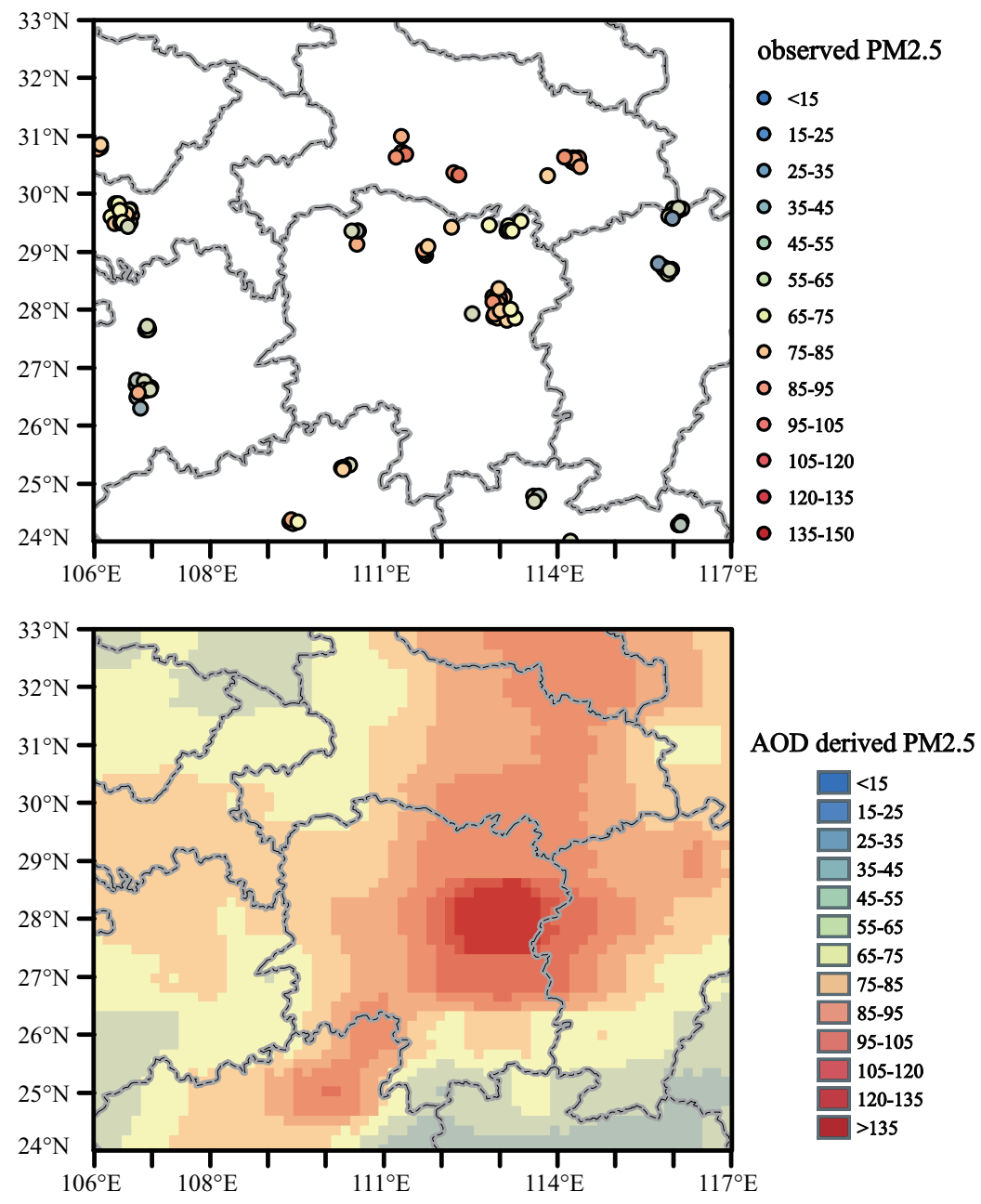

Figure 8. Annual mean observed (top) and estimated (bottom) PM2.5 concentrations for Hunan and Hubei Provinces.

\section{Summary and Conclusions}

In this study, we applied the newly released $3 \mathrm{~km}$ resolution MODIS AOD product to estimate national-scale surface PM2.5 concentrations using a GWR model. Fire emissions and meteorological features were taken into consideration to achieve greater accuracy of PM2.5 estimation.

The results from the performance of the GWR model indicated that the model was relatively accurate in the estimation of ground-level PM2.5 concentrations. The GWR model was able to explain approximately $79 \%$ of the variability in daily PM2.5 concentrations with an RMSE of $18.6 \mu \mathrm{g} / \mathrm{m}^{3}$. 
These results are useful for health risk assessment, air pollution control strategies and environmentally related studies. The results also showed that the GWR model presented in this study has the capacity to identify PM2.5 spatial distributions at various scales. Additionally, the results from mapping national-scale PM2.5 concentrations can be used to support future monitoring construction plans in China.

Acknowledgments: This research was supported by the National Natural Science Foundation of China under Grant Nos. 41275128, 41375063and 41206163. MODIS data were obtained from the Atmosphere Archive and Distribution System at NASA/Goddard Space Flight Center.

Author Contributions: W.Y. and Z.Z. conceived and designed the experiments; L.Z. contributed to the ideas and manuscript writing; W.Y. contributed to the data analysis, interpretation and writing; W.Y. performed the experiments; Y.L. and X.P. analyzed the data; W.W. contributed reagents/materials/analysis tools.

Conflicts of Interest: The authors declare no conflict of interest.

\section{References}

1. Kaufman, Y.J.; Tanré, D.; Boucher, O. A satellite view of aerosols in the climate system. Nature 2002, 419, 215-223. [CrossRef] [PubMed]

2. Pope, C.A., III; Burnett, R.T.; Thun, M.J.; Calle, E.E.; Krewski, D.; Ito, K.; Thurston, G.D. Lung cancer, cardiopulmonary mortality, and long-term exposure to fine particulate air pollution. JAMA 2002, 287, 1132-1141. [CrossRef] [PubMed]

3. Lepeule, J.; Laden, F.; Dockery, D.; Schwartz, J. Chronic exposure to fine particles and mortality: An extended follow-up of the Harvard six cities study from 1974 to 2009. Environ. Health Perspect. 2012, 120, 965-970. [CrossRef] [PubMed]

4. Wan Mahiyuddin, W.R.; Sahani, M.; Aripin, R.; Latif, M.T.; Thach, T.Q.; Wong, C.M. Short-term effects of daily air pollution on mortality. Atmos. Environ. 2013, 65, 69-79. [CrossRef]

5. Ma, Z.; Hu, X.; Huang, L.; Bi, J.; Liu, Y. Estimating Ground-Level PM2.5 in China Using Satellite Remote Sensing. Environ. Sci. Technol. 2014, 48, 7436-7444. [CrossRef] [PubMed]

6. Engel-Cox, J.A.; Hoff, R.M.; Haymet, A.D.J. Recommendations on the use of satellite remote-sensing data for urban air quality. J. Air Waste Manag. Assoc. 2004, 54, 1360-1371. [CrossRef] [PubMed]

7. Koelemeijer, R.B.A.; Homan, C.D.; Matthijsen, J. Comparison of spatial and temporal variations of aerosol optical thickness and particulate matter in Europe. Atmos. Environ. 2006, 40, 5304-5315. [CrossRef]

8. Yap, X.Q.; Hashim, M. A robust calibration approach for PM10 prediction from MODISaerosol optical depth. Atmos. Chem. Phys. Discuss. 2012, 12, 31483-31505. [CrossRef]

9. Wang, J.; Christopher, S.A. Inter-comparison between satellite-derived aerosol optical thickness and PM2.5 mass: Implications for air quality studies. Geophys. Res. Lett. 2003, 30, 2095. [CrossRef]

10. Chu, D.A.; Kaufman, Y.J.; Zibordi, G.; Chern, J.D.; Mao, J.; Li, C.; Holben, B.N. Global monitoring of air pollution over land from the Earth Observing System-Terra Moderate Resolution Imaging Spectroradiometer (MODIS). J. Geophys. Res. 2003, 108, D21. [CrossRef]

11. Van Donkelaar, A.; Martin, R.V.; Park, R.J. Estimating ground level PM2.5 using aerosol optical depth determined from satellite remote sensing. J. Geophys. Res. 2006, 111, D21201. [CrossRef]

12. Gupta, P.; Christopher, S.A. Particulate matter air quality assessment using integrated surface, satellite, and meteorological products: 2. A neural network approach. J. Geophys. Res. 2009, D20205. [CrossRef]

13. Liu, Y.; Paciorek, C.J.; Koutrakis, P. Estimating regional spatial and temporal variability of PM2.5 concentrations using satellite data, meteorology, and land use information. Environ. Health Perspect. 2009, 117, 886-892. [CrossRef] [PubMed]

14. Hu, X.; Waller, L.A.; Al-Hamdan, M.Z.; Crosson, W.L.; Estes, M.G., Jr; Estes, S.M. Estimating ground-level PM2.5 concentrations in the southeastern U.S. using geographically weighted regression. Environ. Res. 2013, 121, 1-10. [CrossRef] [PubMed]

15. Kloog, I.; Chudnovsky, A.A.; Just, A.C.; Nordio, F.; Koutrakis, P.; Coull, B.A.; Lyapustin, A.; Wang, Y.; Schwartz, J. A new hybrid spatio-temporal model for estimating dailymulti-year PM2.5 concentrations across northeastern USA using high resolution aerosol optical depth data. Atmos. Environ. 2014, 95, 581-590. [CrossRef] 
16. Xie, Y.; Wang, Y.; Zhang, K.; Dong, W.; Lv, B.; Bai, Y. Daily estimation of ground-level PM2.5 concentrations over Beijing using $3 \mathrm{~km}$ resolution MODIS AOD. Environ. Sci. Technol. 2015, 49, 12280-12288. [CrossRef] [PubMed]

17. Just, A.C.; Wright, R.O.; Schwartz, J.; Coull, B.A.; Baccarelli, A.A.; Tellez-Rojo, M.M.; Kloog, I. Using High-Resolution Satellite Aerosol Optical Depth To Estimate Daily PM2.5 Geographical Distribution in Mexico City. Environ. Sci. Technol. 2015, 49, 8576-8584. [CrossRef] [PubMed]

18. Gupta, P.; Christopher, S.A.; Wang, J.; Gehrig, R.; Lee, Y.; Kumar, N. Satellite remote sensing of particulate matter and air quality assessment over global cities. Atmos. Environ. 2006, 40, 5880-5892. [CrossRef]

19. Zhang, H.; Hoff, R.M.; Engel-Cox, J.A. The relation between Moderate Resolution Imaging Spectroradiometer (MODIS) aerosol optical depth and PM2.5 over the United States: Ageographical comparison by U.S. protection agency regions. J. Air Waste Manag. Assoc. 2009, 59, 1358-1369. [CrossRef] [PubMed]

20. Wu, Y.; Guo, J.; Zhang, X.; Tian, X.; Zhang, J.; Wang, Y.; Duan, J.; Li, X. Synergy of satellite and ground based observations in estimation of particulate matter in eastern China. Sci. Total Environ. 2012, 433, 20-30. [CrossRef] [PubMed]

21. Song, W.; Jia, H.; Huang, J.; Zhang, Y. A satellite-based geographically weighted regression model for regional $\mathrm{PM}_{2.5}$ estimation over the Pearl River Delta region in China. Remote Sens. Environ. 2014, 154, 1-7. [CrossRef]

22. Lin, C.; Li, Y.; Yuan, Z.; Lau, A.K.H.; Li, C.; Fung, J.C.H. Using satellite remote sensing data to estimate the high-resolution distribution of ground-level PM2.5. Remote Sens. Environ. 2015, 156, 117-128. [CrossRef]

23. You, W.; Zang, Z.; Zhang, L.; Li, Z.; Chen, D.; Zhang, G. Estimating ground-level PM10 concentration in northwestern China using geographically weighted regression based on satellite AOD combined with CALIPSO and MODIS fire count. Remote Sens. Environ. 2015, 168, 276-285. [CrossRef]

24. You, W.; Zang, Z.; Pan, X.; Zhang, L.; Chen, D. Estimating PM2.5 in Xi'an, China using aerosol optical depth: A comparison between the MODIS and MISR retrieval models. Sci. Total Environ. 2015, 505, 1156-1165. [CrossRef] [PubMed]

25. Remer, L.A.; Mattoo, S.; Levy, R.C.; Munchak, L. MODIS 3 km aerosolproduct: Algorithm and global perspective. Atmos. Meas. Tech. 2013, 6, 1829-1844. [CrossRef]

26. Hu, X.; Waller, L.A.; Lyapustin, A.; Wang, Y.; Liu, Y. Improving Satellite-Driven PM2.5 Models with Moderate Resolution Imaging Spectroradiometer Fire Counts in the southeastern U.S. J. Geophys. Res. Atmos. 2014, 119, 11375-11386. [CrossRef]

27. China Environmental Monitoring Center. Available online: http://113.108.142.147:20035/emcpublish/ (accessed on 12 May 2013).

28. Ma, Z.W.; Hu, X.F.; Sayer, A.M.; Levy, R.; Zhang, Q.; Xue, Y.G.; Bi, J.; Lei, H.; Liu, Y. Satellite-based spatiotemporal trends in PM2.5 concentrations: China, 2004-2013. Environ. Health Perspect. 2015, 124. [CrossRef] [PubMed]

29. Levy, R.C.; Mattoo, S.; Munchak, L.; Remer, L.A.; Sayer, A.M.; Hsu, N.C. The collection 6 MODIS aerosol products over land and ocean. Atmos. Meas. Tech. 2013, 11, 2989-3034. [CrossRef]

30. Hsu, N.; Jeong, M.J.; Bettenhausen, C.; Sayer, A.; Hansell, R.; Seftor, C.S.; Huang, J.; Tsay, S.-C. Enhanced Deep Blue aerosol retrieval algorithm: The second generation. J. Geophys. Res. Atmos. 2013, 118, 9296-9315. [CrossRef]

31. The MODIS Level2 Aerosol Products (Collection 6) Referrer to the LAADS Website. Available online: http:/ /ladsweb.nascom.nasa.gov/data/search.html (accessed on 29 September 2012).

32. Giglio, L.; Descloitres, J.; Justice, C.O.; Kaufman, Y.J. An enhanced contextual fire detection algorithm for MODIS. Remote Sens. Environ. 2003, 87, 273-282. [CrossRef]

33. Yan, X.; Ohara, T.; Akimoto, H. Bottom-up estimate of biomass burning in mainland China. Atmos. Environ. 2006, 40, 5262-5273. [CrossRef]

34. Brunsdon, C.; Fotheringham, A.S.; Charlton, M.E. Geographically weighted regression: A method for exploring spatial nonstationarity. Geogr. Anal. 1996, 4, 281-298. [CrossRef]

35. Rodriguez, J.D.; Perez, A.; Lozano, J.A. Sensitivity analysis of k-fold cross validation in prediction error estimation. IEEE Trans. Pattern Anal. Mach. Intell. 2010, 32, 569-575. [CrossRef] [PubMed]

36. Huang, J.P.; Minnis, P.; Chen, B.; Huang, Z.W.; Liu, Z.Y.; Zhao, Q.Y.; Yi, Y.H.; Ayers, J.K. Long-Range Transport and Vertical Structure of Asian Dust from CALIPSO and Surface Measurements during PACDEX. J. Geophys. Res. 2008, 113, D23212. [CrossRef] 
37. Yuan, Y.; Liu, S.; Castro, R.; Pan, X. PM2.5 monitoring and mitigation in the cities of China. Environ. Sci. Technol. 2012, 46, 3627-3628. [CrossRef] [PubMed]

38. Munchak, L.A.; Levy, R.C.; Mattoo, S.; Remer, L.A.; Holben, B.N.; Schafer, J.S.; Hostetler, C.A.; Ferrare, R.A. MODIS $3 \mathrm{~km}$ aerosol product: Applications over land in an urban/suburban region. Atmos. Meas. Tech. 2013, 6, 1747-1759. [CrossRef]

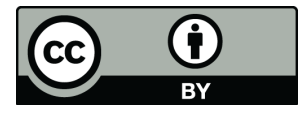

(C) 2016 by the authors; licensee MDPI, Basel, Switzerland. This article is an open access article distributed under the terms and conditions of the Creative Commons by Attribution (CC-BY) license (http://creativecommons.org/licenses/by/4.0/). 